\title{
LA MÀFIA COSA D'HOMES? EL DE LES DONES DINS COSA NOSTRA I EN LES ORGANITZACIONS ANTIMÀFIA
}

\author{
IS THE MAFIA A MALE THING? THE ROLE OF WOMEN INSIDE COSA NOSTRA \\ AND IN THE ANTIMAFIA ORGANIZATIONS
}

Eva Virgili Recasens

Universitat Rovira i Virgili, Tarragona

\section{RESUM:}

La màfia és una organització criminal tant masculina com femenina. Això ho sabem perquè hi ha hagut dones que han volgut trencar els seus lligams amb la màfia i han aportat informació útil a la justícia sobre el fenomen mafiós. El rol de la dona dins la màfia consisteix en transmetre $i$ garantir la perpetuació del codi cultural i els valors de la cultura mafiosa en els seus fills i en augmentar la riquesa mitjançant el tràfic de droga i la gestió de contractes.

\section{PARAULES CLAU:}

Màfia, dona, Cosa Nostra, home.

\section{ABSTRACT:}

Mafia is a criminal organization for both male and female. We know this because there have been women who have wanted to break their ties with the Mafia and have provided useful information to justice about the mafia phenomenon. The role of women in the Mafia is to convey and guarantee the perpetuation of cultural code and the values of mafia culture in their children and increase wealth through drug trafficking and contract management.

\section{KEY WORD:}

Mafia, woman, Cosa Nostra, man. 
L'eix fonamental d'aquesta xerrada neix de la necessitat de donar resposta a la pregunta inicial (la màfia és cosa d'homes?), sorgida de la reiterada afirmació: la màfia és una organització "absolutament masculina"1.

Fins a quin punt però les esposes dels boss estan isolades dels entramats mafiosos? és possible que visquin aillades de la realitat que les envolta?

Les declaracions de les penedides ${ }^{2}$ han demostrat que estan al corrent $\mathrm{d}^{\prime}$ allò que passa al seu entorn, les dones gestionen la casa, saben qui entra i qui en surt, són elles les que preparen les recepcions i les reunions familiars. És evident doncs, que no podem acceptar la premissa que afirma que les dones no formen part de la màfia ${ }^{3}$, així les dones són responsables d'allò que succeeix al seu entorn, són elles les que accepten i silencien la activitat dels seus homes.

Però quin és l'autèntic rol de les dones de màfia?

1) Simbologia mafiosa, simbologia femenina: La màfia és un grup marcat per una forta ambivalència respecte el femení:

- La unió dels mafiosos, a través del ritu d'iniciació, a la mammasantissima, a Cosa Nostra, reflexa la visió de les mares com a figures santes "el secret que uneix els membres de l'associació, l'omertà, és l'arma utilitzada contra el pare, la llei, l'estat, l'exterior i que defensa l'interior, la mare concebuda com la única cosa bona, una mammasantissima"4. Parel-lament el ritu d'iniciació representa el pas del nen al món dels homes "mamar la llet materna feminitza mentre beure el líquid masculí, la sang5, virilitza" 6 .

- La forta omofòbia que marca l'associació mafiosa és una estratègia per evitar l'acceptació de la part passiva, identificada amb el femení, la qual cosa ens ho exemplifica la forta aversió que senten per la homosexualitat. La necessitat d'allunyarse dels valors femenins, podria ser una necessitat vers la qual es veu empès l'home per deslligar-se del fort poder matern, ja que per la mare el fill mascle és la única manera de participar en la vida pública.

1 Falcone G. Padovani M. Cose di Cosa Nostra, Rizzoli, Milano 1991, pèg.23

2 Tot i que es parla de penedides de màfia en referència a les dones dels mafiosos que han declarat davant la justícia, dit terme hauria de ser revisat, ja que si les dones no formen part de la organitzaciô mafiosa, en cap cas poden ser penedides, sinó colllaboradores de justícia.

3 Entenec aquí la màfia com una organització criminal i no com un complex cultural.

4 Siebert, Renate Siebert R., Le donne, la mafia, Il Saggiatore, Milano 1994, pàg46

5 Durant el ritual es fa una incisió a la mà amb la qual dispara l'íniciat i de la gota de sang que en surt es tenyeix una imatge santa, normalment l'Annunziata, que es creu que és la patrona de Cosa Nostra.

6 Siebert, Renate (1994: 32)
2) Les padrines. Tot i que la majoria d'estudis exclouen a les dones del que podríem anomenar la cúpula organitzativa de Cosa Nostra, això no implica que les dones visquin aillades del món que les envolta.

Si partim de l'afirmació que la màfia és una barreja de tradició i innovació, per què hauríem de pensar que el procés d'emancipació femenina ha deixat al marge a les dones de Cosa Nostra?

Són diverses les activitats que han realitzat les dones en el context mafiós:

-Prestanoms. Aquesta activitat s'ha de relacionar amb l'augment de riquesa produïda pel tràfic de droga, ja que fins la llei La Torre ${ }^{7}$, aquestes dones eren considerades víctimes innocents o còmplices sense saber-ho, els jutges consideraven a les esposes, filles, mares o germanes de mafiosos "menors d'edat", de tal manera que no eren investigades quan els seus noms figuraven en els contractes i béns patrimonials dels seus familiars mafiosos.

- Les dones han participat i participen en el tràfic de droga a petita escala, on s'ajuden moltes vegades dels seus fills, i a gran escala, on són diverses les veus de dones; Annamaria Cordovino, Vicenza Calí, Esmeralda Ferrara o Tiziana Augello entre altes, que expliquen les seves experiències en el tràfic de droga entre els EUA i Sicília.

- Les dones supplenti (suplents) que única i exclusivament gestionen els negocis del marit quan aquest és a la presó, com el cas de Maria Filippa Messina.

3)Transmissores dels valors mafiosos i de cert consens social. Important és el paper que ha tingut la dona en la repetició i reforçament dels valors culturals, és ella qui ha garantit i continua garantint la perpetuació del codi cultural i en aquest cas, dels valors i la cultura mafiosa, és ella, i més en la societat tradicional, qui educa als fills. Així afirmem que les dones són a la vegada víctimes i mediadores de la cultura mafiosa com ho són de la cultura sexista.

4) Les dones antimàfia

Entre elles cal fer diverses distincions i estudiar els processos socials, econòmics i culturals que les han portat a adoptar aquest paper:

- Les dones dels penedits de màfia. Mentre que algunes d'elles han pres distància respecte els seus, ja sigui perquè es veuen incapaces de revelar-se contra un destí senyalat o per la seva voluntat manifesta de persistir en un món que coneixen, altres han optat per continuar els passos dels seus marits penedits i aportar informació sobre el fenomen mafiós la qual cosa, les fa col-laboradores de la justícia i en conseqüència dones antimàfia.

7 Legge La Torre: Estén als familiars i als que presten el seu nom als mafiosos les investigacion patrimonials amb la finalitat de confiscar els béns dels quals no vingui provada la legítima propietat. 
- Dones de màfia que es dirigeixen a la justícia. Aquestes dones opten per trencar tots els seus lligams amb el món anterior, són dones que es revelen contra la condició en què es troben, que opten per trencar l'omertà ja sigui després de la mort d'algun ser pròxim o de forma voluntària. Entre aquestes els noms són abundants, però m'agradaria sobretot anomenar a Felicia Impastato,a Michela Buscemi i Rita Atria.

- Dones de fora de l'ambient mafiós que es dirigeixen a la justícia. Aquests casos són menors i cal destacar particularment a Anna Pecoraro i a Maria Benigno.

Per què les dones que es dirigeixen a la justícia, i principalment les que provenen d'ambients mafiosos, ho fan després de la mort d'algun familiar, marit o amic? Podem interpretar aquesta collaboració com una forma de venjança?, Per què esperen la mort d'algú pròxim abans de dirigir-se a la justícia? Després d'aquest petit anàlisi sobre la temàtica considero oportú afirmar, que les dones tenen un paper i un rol dins la organització mafiosa com el tenen en els altres aspectes de la societat.

\section{BIBLIOGRAFÍA}

Dondoni, M., Licari, G., Faccio, E., \& Pellicciotta, A. (2006). Identità e normatività gruppali nella cultura siciliana e nella sub-cultura di Cosa Nostra. Narrare i gruppi. Prospettive cliniche e sociali, 1, 1-22.

Falcone G. Padovani M. (1991) Cose di Cosa Nostra. Rizzoli: Milano.

Pizzini Gambetta, V. (2002). Uomini e donne di Cosa Nostra, Lettera Internazionale, Rivista trimestrale di letteratura.

Scarpinato, R. Focus sul pensiero mafioso. website: www. narrareigruppi. it, 5.

Siebert, Renate Siebert R (1994). Le donne, la mafia. Il Saggiatore: Milano.

Storti, L. (2004). Mafie organizzate. Cosa Nostra e Yakuza in visione comparata. Quaderni di Sociologia, (34), 77-101.

Svezia, E. (2014). Le donne nella rete di" Cosa Nostra". Università degli studi di Catania: Catania.

Tarda, M. (2005). Le donne di Cosa Nostra: tra stereotipi e realtà. Università degli studi di Catania: Catania. 